IOSR Journal of Engineering

e-ISSN: 2250-3021, p-ISSN: 2278-8719,

Vol. 2, Issue 12 (Dec. 2012), ||V4|| PP 01-07

\title{
Design and performance evaluation of solar tunnel dryer for tomato fruit drying in Zimbabwe
}

\author{
L. Kagande ${ }^{1}$, S. Musoni ${ }^{2}$ and J. Madzore ${ }^{3}$ \\ ${ }^{1}$ Lecturer, Renewable Energy, Department of Mechanical Engineering, University of Zimbabwe, P.O. Box MP \\ 167, Mt Pleasant, Harare, Zimbabwe \\ ${ }^{2}$ Lecturer, Department of Agricultural Engineering, University of Zimbabwe, P.O. Box MP 167, Mt Pleasant, \\ Harare, Zimbabwe \\ ${ }^{3}$ Research scientist, Scientific Industrial Research Development Centre (SIRDC), Hatcliffe, Harare, Zimbabwe.
}

\begin{abstract}
Vegetable drying is the concentration of dry matter through the reduction of free water to a level that prohibits water activity without destroying the tissue, edibility or aesthetic appearance of the fruit. Tomatoes are produced in Zimbabwe in abundance during the dry season but over $60 \%$ rots in the farms especially among the small scale farmers according to Odunfa. Cheaper drying technologies that use readily available, uninterrupted clean source of energy is hereby being offered to the farmers, hence a solar tunnel dryer was designed and constructed at Zimbabwe's Scientific Research and Development Centre (SIRDC) at a cost of US\$500 recoverable in less than a single season, with a batch capacity of $50 \mathrm{~kg}$. Moisture content of sliced tomatoes was reduced from $94.09 \%$ to $20.50 \%$ on dry basis $(93.70 \%$ to $6.29 \%$ wet basis) using air temperature in the range 32.6 to $56^{\circ} \mathrm{C}$ in a solar tunnel dryer over a period of 15 hours. The yield was $0.067 \mathrm{~kg}$ dry matter per $\mathrm{kg}$ of wet tomatoes which is $6.28 \%$. The mean ambient conditions for wind speed, relative humidity and insolation were $0.77 \mathrm{~m} / \mathrm{s}, 29 \%$ and $558.30 \mathrm{~W} / \mathrm{m}^{2}$ respectively. Results showed that the technology can be easily adopted for profitable use by the farming enterprise for both small and large scale farmers in Zimbabwe.
\end{abstract}

\section{INTRODUCTION}

Agriculture dominates Zimbabwe's economy despite the fact that its contribution to Gross Domestic Product (GDP) is less than $20 \%$. Agriculture provides an income to about $75 \%$ of the country's 12.5 million population, approximately $70 \%$ of which reside in rural areas (Ministry of Public Service, Labour and Social Welfare, Social Development Fund Unit, 1997).

One of the most profitable cash crops grown among Zimbabwean small scale and commercial farmers is the tomato. Not only are tomatoes delicious, they also have many nutritional benefits. Tomatoes help in the prevention of cardio-vascular disease and enhance cancer-fighting abilities. Tomatoes are rich in phytochemicals and research has shown that phytochemical lycopene which is found in tomatoes is a powerful antioxidant. (C Vasse, 2006). Lycopene's benefit against heart disease is due to its antioxidant effects on LDL cholesterol oxidation,(J Teta, et.al, 2005). Lycopene is a carotenoid that gives tomatoes their red colour. However, tomato volumes are at their peak in December when they will be selling at US \$1.00 per 25-litre bucket or even for 2 such buckets. During off season the same volume will be costing US $\$ 25$ which is a $2400 \%$ to $2450 \%$ price increase at Mbare Msika, Harare, the largest horticultural market place in Zimbabwe. Despite all the health benefits of tomatoes, their seasonal availability and price fluctuations reduce the full benefits of their consumption. In 2010 Zimbabwe imported 603000 tonnes of fresh tomatoes from South Africa to meet its local deficit, (Source: A Profile of South Africa Tomato Value Chain, 2011). Seasonality of tomatoes in Zimbabwe's communal areas often leads to depressed market prices and wastage (Murphy, 1996). As long as long term storage facilities remain inadequate in Zimbabwe, farmers must look to processing as a means of overcoming gluts on markets that drive low (Odunfa, 1995).

At the current time, losses of fresh tomatoes due to spoilage are significant and as a result small-scale producers in Zimbabwe typically have limited access to higher value markets in urban areas. Odunfa observed losses as high as 60\% in fruits and vegetables, between 40 and 50\% for roots and tubers, and losses of $20 \%$ for grains (Odunfa, 1995). Most of these losses are postharvest losses owing to the over-ripening, senescence or exposure to unfriendly environments before the produce reaches its market. Further, even in circumstances where small-scale producers can access markets, returns on unprocessed products are typically low. Processing of horticultural products using appropriate technologies is seen as a mechanism to reduce spoilage and add value to and, in turn, enhance the livelihood of poor small-scale producers. Without drying of fresh tomatoes much of the produce would go to waste before consumption. The processing of foods, whether by dehydration, canning 
or freezing for example, has the added benefit (in many cases) of rendering raw food microbiologically safe (UN, 1998)

It has been demonstrated that agro-processing activities are an effective way of reducing poverty and improving the quality of life of marginalised people (Richter, Basler and Frazen, 1996; McPherson, 1991). Agro-processing activities can contribute to sustainable livelihoods through improved incomes, employment, food availability, nutrition and social and cultural well-being. The Food and Agriculture Organisation, FAO (1995) has highlighted that value added through marketing and processing raw products can be much greater than the value of primary production itself. On-farm processing of tomatoes can involve preservation through drying. Drying reduces moisture content of tomatoes and thus reduces water activity and deterioration. Drying also reduces volume of crop whilst maintaining the nutritional value and improving on handling.

Sun-dried tomatoes are a flavorful addition to salads, pastas and pizzas. Originally developed in Italy as a way to preserve tomatoes for use in the winter, sun-dried tomatoes contain the same nutritional value as the fresh equivalents and have lycopene and antioxidant content like fresh tomatoes, they are also rich in certain key minerals, (A Dave, 2011)

This research explores the prospects of using solar tunnel drier in drying tomatoes in Zimbabwe through the development of a prototype modelled along the Hoheinhmer dryer5. Evaluation of the performance of the solar tunnel drier was done by conducting load and no load tests by measuring ambient air temperature, ambient relative humidity, solar radiation, collector and dryer temperature, collector and dryer relative humidity, wind speed, photovoltaic power output and moisture.

\section{CONTEXT}

Tomato processing is common among small-scale producers in Zimbabwe. It is a relatively simple task, especially when carried out on a small-scale. Usually tomatoes are either sun-dried (sliced and spread to dry) or pulped. In the case of pulping, tomatoes are selected according to ripeness, and then washed. They are then pulped in an electrically driven mechanical pulper which separates the pulp from seeds and skins. The juice is then heated in a stainless steel pan at up to $90 \mathrm{C}$ over an open gas fired stove. The juice is checked for acidity, which should be below $\mathrm{pH}$ 4.5. The juice can then be graded to meet various standards before being treated with preservatives, e.g. sodium metabisulphite. The extract is then packed in tins or drums, and stored at a temperature between 25 and $30^{\circ} \mathrm{C}$, ready for consumption.

Traditional drying methods include drying by direct sunlight or for example in the case of small amounts of food, drying over a kitchen fire. Some techniques involve use of solar dryers. (ITDG Technical Brief) Osmotic drying and crystallising- fruit is heated in sugar syrup to extract moisture before drying in air. Sun drying is usually done in August, September and October as rainfall is expected in November to March. Pounding is further done to produce powder. This enables the product to be stored for a lengthy period, (Turner et.al, 1999, Murphy, 1996, Fellows, 1997,) . Products from processed tomatoes include tomato paste and sun dried tomatoes which are sold for local consumption and export. Drying is possibly the most appropriate way of preserving tomatoes on-farm as it is a low-cost practice. Drying process represents one of the earliest techniques used to process fruit and vegetables. More advanced drying methods such as the use of artificial dryers have been developed which ensure greater control over the drying process, have greater capacity and enable a wider range of products to be dried. However there are some disadvantages to artificial dryers. Artificial drying requires greater capital investment as production costs are higher owing to fuel, equipment spares and maintenance costs. Furthermore the skills required to maintain such may not be readily available locally. Mechanised techniques are usually applicable for use in urban or peri-urban areas where there is better access to these inputs. A DTC (Development Technology Centre, a University of Zimbabwe unit)-developed solar drier is capable of drying $12 \mathrm{~kg}$ of leafy greens or cabbages in 1.5-2 days, with drying time reduced to one day for a capacity of $4 \mathrm{~kg}$ of produce. The drier consists of a rectangular framework raised $300 \mathrm{~mm}$ above ground. The base is covered with perforated shaded cloth and supported so that it should not sag from the weight of the vegetables. Another shade cloth is placed on top, $200 \mathrm{~mm}$ above the layer of vegetables to cover the whole dryer and keep out flies and dirt.(DTC, 1989).

This study explored the drying of tomatoes with the use of solar tunnel dryers as they have the advantage of creating higher temperatures and air movement that increases the rate of dying. The higher drying rate ensures a greater quantity of produce to be dried in a relatively small period of time.

\section{MATERIALS AND METHODS}

A solar tunnel drier was designed and constructed at SIRDC, Zimbabwe, see Fig 1 below. Tomatoes with no prior treatment other than rinsing with water were sorted based on uniformity of ripeness after which they were then sliced to between $3-5 \mathrm{~mm}$ thick slices. They were placed in a tray making a single layer. The tray mass was initially measured and taken out every two hours to measure the moisture loss. Hourly measurements 
of the parameters given in table 1 below were recorded. The drying time was from 8:00 Hrs to 17:00 Hrs. No load and load measurements were taken and the variations with time are shown graphically (Fig.4 below).

Table1 Parameters measured and instrumentation used

\begin{tabular}{|l|l|}
\hline Parameter & Instrumentation and Specification \\
\hline Temperature & Philip Haris Temperature sensormeter, model E30700/8 \\
\hline Relative Humidity & Philip Haris Relative Humidity sensormeter, model E30200/9 \\
\hline PV Module Output & Digital Multimeter \\
\hline Initial Moisture & Gallenkamp Economy Incubator Size 2 \\
\hline Weight Loss & Sartorius model LA 34001 S (0-30kg scale) \\
\hline Solar Radiation & Solar Radiation Pyranometer, Meteorological Services Dept, Belvedere \\
\hline Wind Speed & Cup anemometer, Meteorological Services Dept, Belvedere \\
\hline
\end{tabular}

\section{Moisture level Determination}

Weight loss is measured and is used to calculate the moisture content and the drying rate using equations below: $\mathrm{mc}_{\mathrm{wb}}=\mathrm{w}_{\mathrm{tw}} /\left(\mathrm{w}_{\mathrm{tw}}+\mathrm{w}_{\mathrm{tdm}}\right) \times 100$

$\mathrm{mc}_{\mathrm{db}}=\left(\mathrm{w}_{\mathrm{tw}} / \mathrm{w}_{\mathrm{tdm}}\right) \times 100$

where: $\mathrm{mc}_{\mathrm{wb}}=$ moisture content on wet basis, $\mathrm{w}_{\mathrm{tw}}=$ total mass of water, $\mathrm{w}_{\mathrm{tw}}=$ total mass of water, $\mathrm{w}_{\mathrm{tdm}}=$ total dry matter mass

Moisture content on dry basis is preferable to moisture content on wet basis in research work since in the latter, both the moisture content and the basis on which it is computed changes as the drying proceeds thus tends to give inaccurate results. The two however are related by the following expression:

$$
\begin{aligned}
& \mathrm{mc}_{\mathrm{wb}}=\mathrm{w}_{\mathrm{tw}} /\left(\mathrm{w}_{\mathrm{tw}}+\mathrm{w}_{\mathrm{tdm}}\right) \times 100 \\
& \mathrm{mc}_{\mathrm{db}}=\left(\mathrm{w}_{\mathrm{tw}} / \mathrm{w}_{\mathrm{tdm}}\right) \times 100
\end{aligned}
$$

where: $\mathrm{mc}_{\mathrm{wb}}=$ moisture content on wet basis, $\mathrm{w}_{\mathrm{tw}}=$ total mass of water, $\mathrm{w}_{\mathrm{tw}}=$ total mass of water, $\mathrm{w}_{\mathrm{tdm}}=$ total dry matter mass

\section{Dryer Design Features}

\section{CYLINDRICAL SULAR TUNNEL DRIER}

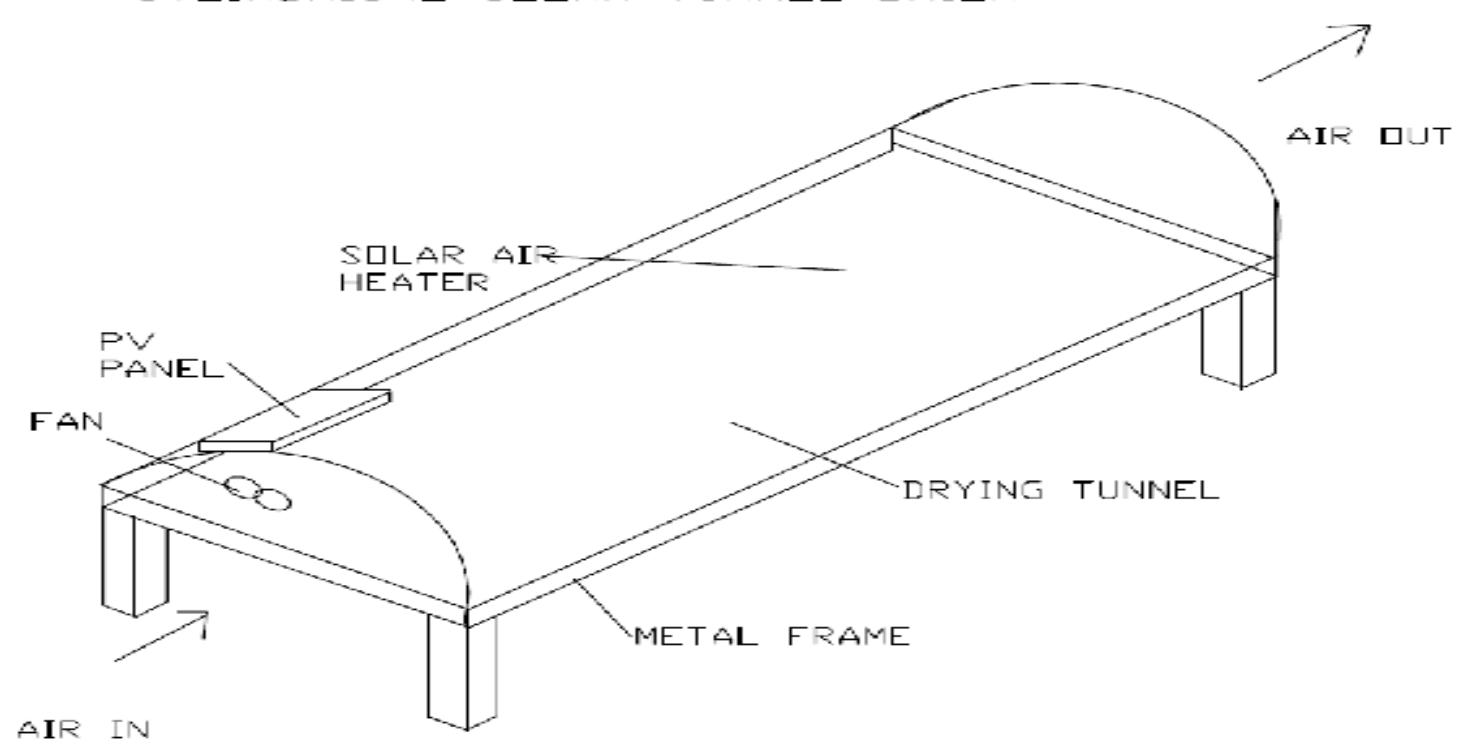

Figure 1 solar tunnel drier

Drying area $=8.1 \mathrm{~m}^{2}$, Thermal Collector Area $7.2 \mathrm{~m}^{2}$

Black polythene sheeting $(200 \mu \mathrm{m})$ is used as the thermal absorber, while the transparent one is used for covering both the thermal collector area and the drying area. Cardboard paper is used as the back insulator 
on the absorber sheeting. The dryer frame and trays are both made from wood (and plywood), but, if durability is desired, from metal, painted to prevent corrosion. The dryer is placed along, or in parallel with an East - West axis to maximise its exposure to solar radiation and slightly tilted at $3^{0}$ to induce natural air flow when the fan is not triggered by the higher dryer temperature. The solar photovoltaic (PV) driven fan is used for forced air circulation to enhance drying. The thermostat control is set at a temperatutre of $60{ }^{\circ} \mathrm{C}$. Moisture control in the product is achieved by regulation of the drying process based on intensity of solar radiation.

The dryer can process $50 \mathrm{~kg}$ of fresh tomatoes in about 15 hours (i.e. about 2 working days)
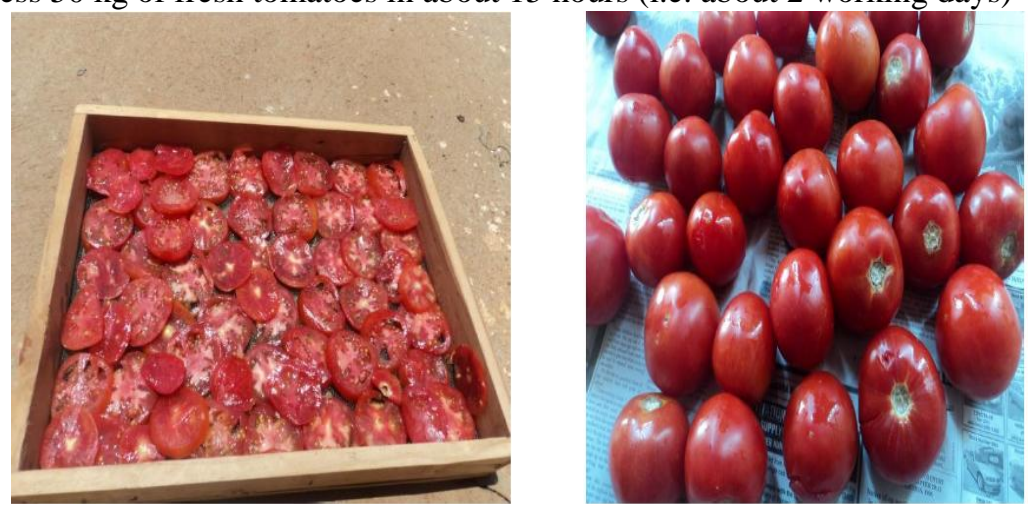

Fig 2 Tomatoes for solar tunnel drying (before slicing)

\section{RESULTS AND DISCUSSION}

The drying process was stopped after no further change in mass was observed. At this point, moisture content decreased from $94.09 \%$ to $20.50 \%$ on dry basis $(93.70 \%$ to $6.29 \%$ wet basis) using air temperature in the range 32.6 to $56{ }^{\circ} \mathrm{C}$ in a solar tunnel dryer over a period of 15 hours. The yield was $0.067 \mathrm{~kg}$ dry matter per $\mathrm{kg}$ of wet tomatoes which is $6.28 \%$. The mean ambient conditions for wind speed, relative humidity and insolation were $0.77 \mathrm{~m} / \mathrm{s}, 29 \%$ and $558.30 \mathrm{~W} / \mathrm{m}^{2}$ respectively.

Figure 3 below shows samples of the product after both solar tunnel and oven drying.

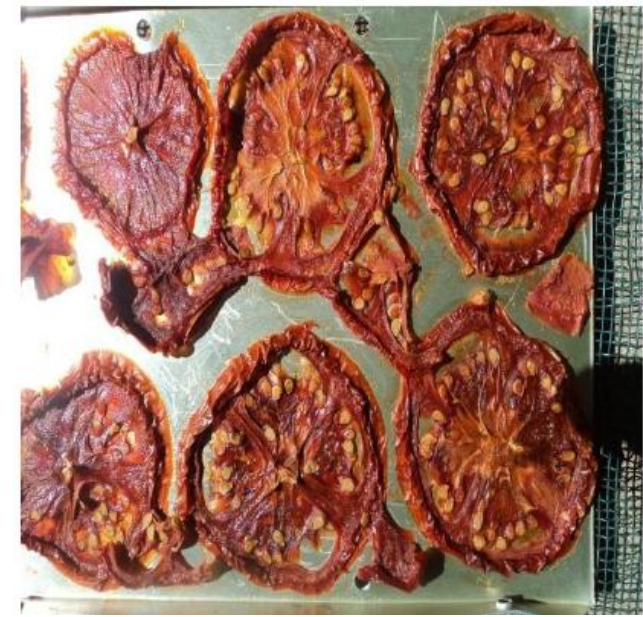

(a) Oven dried tomatoes

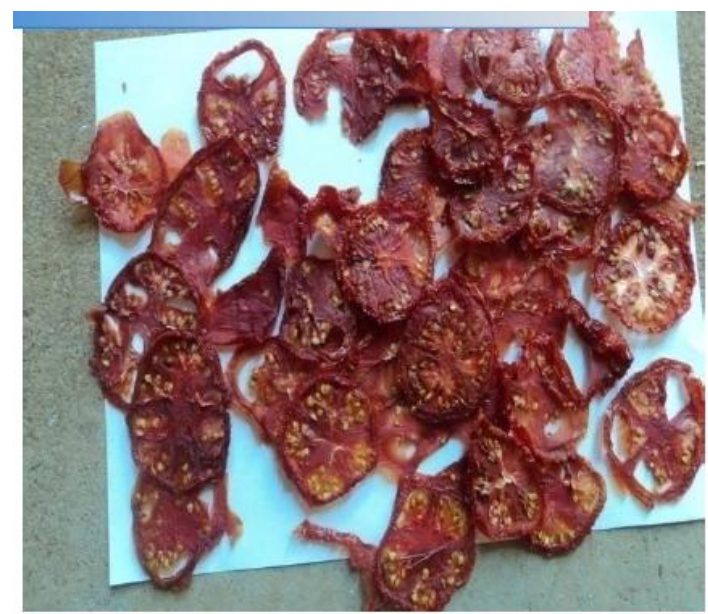

(b) Solar Tunnel dried tomatoes

Fig3 Color differences between oven dried and solar dried tomatoes 


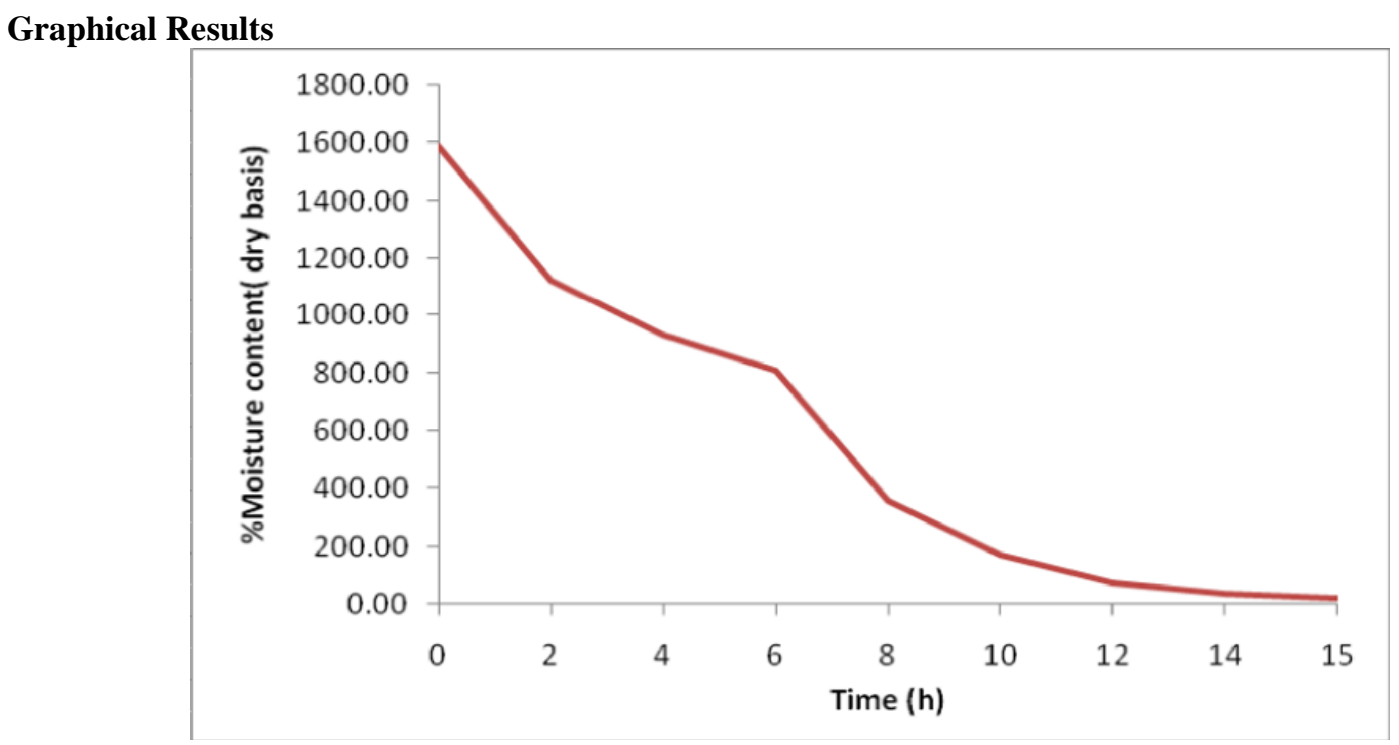

Figure 4 Variation of moisture content with time

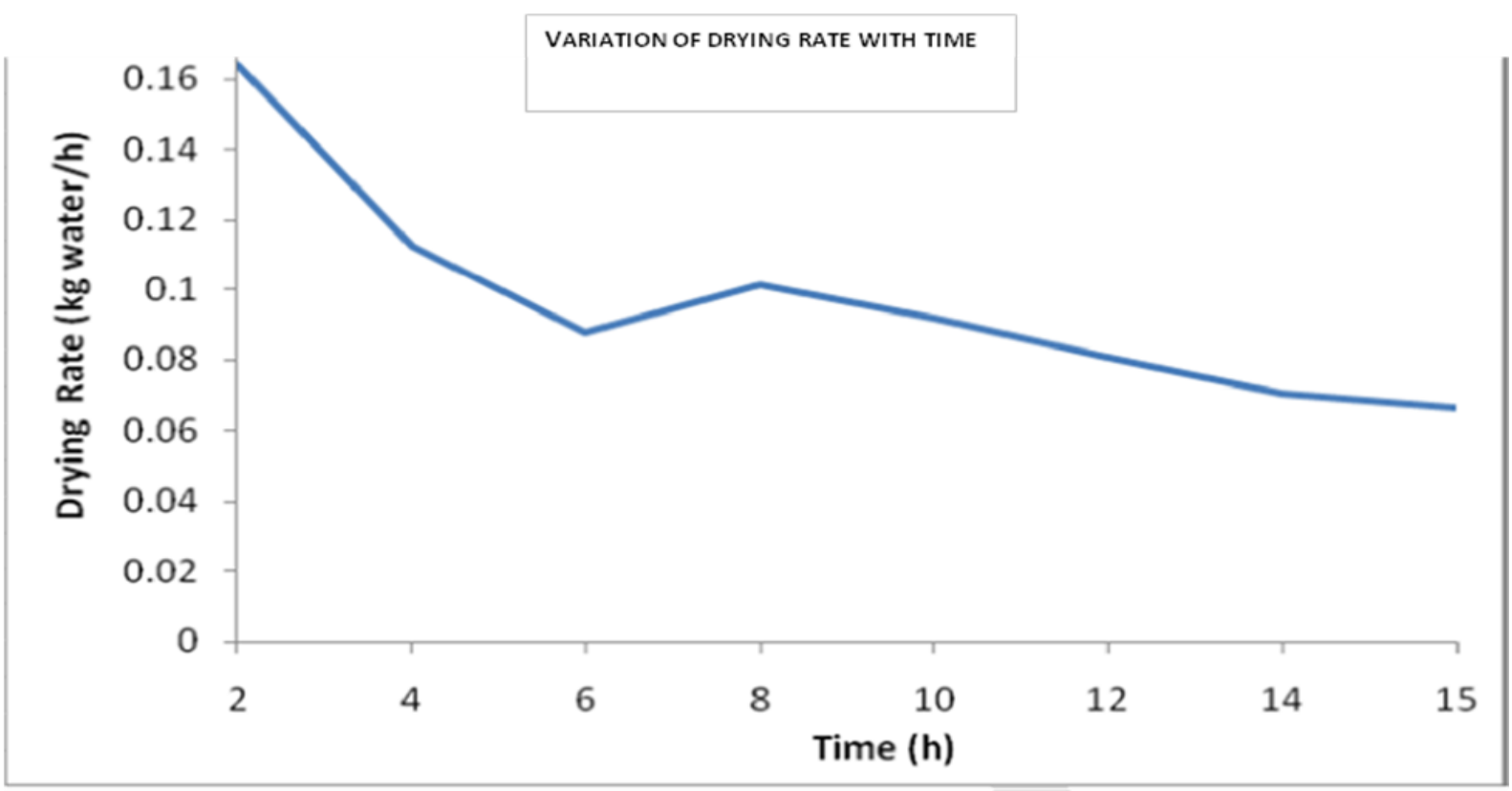

Figure 5 Variation of Drying Rate with Time

The drying rate shows the falling rate phase characterised by a fast or rapid initial rate. This is a constant drying rate phase. This is indicative of diffusion as the most significant process governing the rate of internal moisture migration to the surface for evaporation. It was observed that the initial drying rate was $0.164 \mathrm{~kg} \mathrm{water} / \mathrm{h}$ and at the end of the test run the drying rate fell to $0.066 \mathrm{~kg}$ water/h The inconsistence shown between the hours of 6 and 8 is due to the fact that after the 6th hour solar drying was stopped and the product was left overnight under ambient conditions for drying the next day. Initial rate is high due to removal of surface and free moisture. Resumption of the drying process saw an increase in drying rate due to increased moisture availability at the surface from overnight internal moisture migration to the surface. After this the rate falls again as migration of internal moisture to the surface is affected by both the rate of diffusion and case hardening. As the drying progresses, the evaporation rate decreases, with less evaporative cooling, and the product's internal temperature increases. Decolourisation and formation of off-flavours may occur with high internal temperatures towards the end of the drying process. This was the reason for the use of a thermostat to regulate the temperature to below $60^{\circ} \mathrm{C}$. Quality issues such as any changes in colour, taste, flavour and drying rates between solar-dried and ovendried tomatoes are compared in Table 2 below, and the weight in $\mathrm{kg}$ per batch dried in a given time are shown as indications of drying rates (Table 2 below). 
Design and performance evaluation of solar tunnel dryer for tomato fruit drying in Zimbabwe

Table 2 Comparison of solar dried to oven dried tomatoes

\begin{tabular}{|c|c|c|}
\hline $\begin{array}{l}\text { PARAMETER } \\
\text { COMPARISON }\end{array}$ & SOLAR-DRIED TOMATOES & $\begin{array}{l}\text { OVEN-DRIED TOMATOES 50- } \\
60^{\circ} \mathrm{C}\end{array}$ \\
\hline DRYING RATE & $\begin{array}{l}50 \mathrm{~kg} \text { fresh tomatoes takes } 15 \\
\text { hours to be dried }\end{array}$ & $\begin{array}{l}\text { Temperature-dependent. At range } \\
\text { of } 55-60^{\circ} \mathrm{C} \text {, same as solar dried: } \\
\text { higher temperatures reduce drying } \\
\text { time at the expense of quality.\& } \\
\text { vice-versa }\end{array}$ \\
\hline COLOUR & Red colour maintained & Darker in colour. Dark brown. \\
\hline FLAVOUR (QUALITATIVE) & Rich in flavour & Off-flavour \\
\hline TASTE (QUALITATIVE) & Taste good & A little inferior in taste \\
\hline
\end{tabular}

Preservation of food by drying is a common practice in different parts of the world and it is used to extend the shelf life of food products. Drying allows food to be preserved by removing the moisture in the food, in order to prevent the growth of microorganisms that cause deterioration (Mukhtar, 2009). In this study, the solar drying method used was capable of removing $73.9 \%$ of the moisture from tomatoes. Reduction in the moisture content as observed in this study decreases the perishability of these food crops, adds value and also extends the shelf life, thereby making them available throughout the year, and allowing farmers to take advantage of lucrative times for selling their produce after greatly minimising on post-harvest losses that would occur through rotting.

\section{CONCLUSION AND RECOMMENDATIONS}

High quality and aesthetically appealing dried tomatoes can be produced from solar tunnel drying. Solar dryers have the advantage of creating higher temperatures and movement of air that increases the rate of drying, therefore reducing the risk of spoilage by micro-organisms. Food is enclosed in the drier keeping contamination (by dust, insects and animals for example) at a minimum. The higher drying rate enables a greater quantity of produce to be dried in a relatively short space of time. Drying by natural means avoids the discoloration that occurs with artificial drying methods caused by high temperatures. However, there are also some drawbacks to solar drying. This process takes longer than oven controlled drying. This drying method is also dependant on weather conditions which include: humidity, insolation intensity and wind speed unlike artificial drying methods where drying conditions can be controlled. Solar dryers also demand a greater labour input than traditional methods, e.g. loading and unloading of trays of produce, but above all, the structure can be cheaply constructed using simple and affordable technologies and capable of being made and repaired in the areas where they are to be adopted, and are constructed using simple tools and limited locally-available resources. No special skills are required. Dried tomatoes need to be rehydrated to improve on texture so that their quality matches that of fresh foods. There is need to taste the nutrional differences between fresh, oven dried, sun dried and solar dried tomatoes to assess any nutritional losses due to this processing technique.

\section{REFERENCES}

1). FAO (1995) Food for consumers: Marketing, processing and distribution. Rome: FAO.

2). Ministry of Public Service, Labour and Social Welfare (Social Development Fund Unit) (1997) 1995 Poverty Assessment Study Survey: Main Report. Harare: Ministry of Public Service, Labour and Social Welfare.

3). Odunfa, A. (1995) Structure, potential and constraints of small-scale food processing in Africa.

4). Richter, J., Basler, A. and H. Franzen (eds) (1996) Small-Scale Food Processing Contributing to Food Security. Food and Agriculture Development Centre (ZEL/ATSAF/DSE).

5). FAO Crop Calender: Available athttp://www.fao.org/agriculture/seed/cropcalendar/searchbycountry.do

6). Cheryl Vasse ,Health Benefits of Tomatoes, 2006

7). Jade Teta, ND, CSCS; Keoni Teta ND, LAc CSCS; and Julie Sutton ND, LAc, CSCS, 2005Tomatoes and Tomato Products as Medicine can also be accessed at: www.naturopathichealthclinic.com

8). Adam Dave, 2011, The nutritional information of sun dried tomatoes

9). http://www.livestrong.com/article/385830-the-nutritional-information-of-sun-driedtomatoes/\#ixzz22Hq71hvJ

10). A Profile of South Africa Tomato Value Chain, 2011

11). Murphy, A. (1996) Fruit and Vegtable drying: Opportunities for Micro-enterprise Developemnet in the Communal Areas.Draft sub-sector report, Department of Food Economics, University of College Cork, Ireland.

12). UN (1998) International Market Acces Information Horticulture Sector. Geneva:UN 
13). Turner, A and Civinge, O. (1999) Production and Marketing of Horticultural Criops in Zimbabwe:A survey of Smallholder Farmers in the Mashonaland East Province.Ithaca:Cornell International Institute of Food, Agriculture and Dveleopment (CIIFAD)

14). Fellows, P.(1997)Traditional Food Processing for Profit. London:Intermediate Technology Publications.

15). Develoment Technology Centere (DTC) (1989) Improvement and Expansion of Horticulture in Communal Areas of Zimbabwe. Project ZIM/86/021. Progress report for 31 December. University of Zimbabwe

16). Mukhtar, F.B., 2009. Effect of storage temperature on post harvest deterioration of banana and plantain (Musa sp.). Int. J. Phys. Applied Sci., 3: 28-38. 